\title{
Application of Functional Data Analysis and FTIR-ATR Spectroscopy to Discriminate Wine Spirits Ageing Technologies
}

\author{
Ofélia Anjos ${ }^{1,2,3, *}$, Miguel Martínez Comesaña ${ }^{4}$, Ilda Caldeira ${ }^{5,6}{ }^{\circledR}$, Soraia Inês Pedro ${ }^{1}$, \\ Pablo Eguía Oller ${ }^{4}\left(\mathbb{D}\right.$ and Sara Canas ${ }^{5,6} \mathbb{D}$ \\ 1 Instituto Politécnico de Castelo Branco, Escola Superior Agrária, 6001-909 Castelo Branco, Portugal; \\ soraia_p1@hotmail.com \\ 2 CEF, Instituto Superior de Agronomia, Universidade de Lisboa, 1349-017 Lisboa, Portugal \\ 3 CBPBI, Centro de Biotecnologia de Plantas da Beira Interior, 6001-909 Castelo Branco, Portugal \\ 4 Department of Mechanical Engineering, Heat Engines and Fluid Mechanics, Industrial Engineering School, \\ University of Vigo, Maxwell s/n, 36310 Vigo, Spain; migmartinez@uvigo.es (M.M.C.); \\ peguia@uvigo.es (P.E.O.) \\ 5 INIAV, INIAV-Dois Portos, Quinta da Almoínha, 2565-191 Dois Portos, Portugal; ilda.caldeira@iniav.pt (I.C.); \\ sara.canas@iniav.pt (S.C.) \\ 6 MED-MediterraneanInstitute for Agriculture, Environment and Development, Instituto de formação \\ avançada, Universidade de Évora, Pólo da Mitra, Ap. 94, 7006-554 Évora, Portugal \\ * Correspondence: ofelia@ipcb.pt; Tel.: +351-272-339-900
}

Received: 28 April 2020; Accepted: 27 May 2020; Published: 2 June 2020

\begin{abstract}
Fourier transform infrared spectroscopy (FTIR) with Attenuated Total Reflection (ATR) combined with functional data analysis (FDA) was applied to differentiate aged wine spirits according to the ageing technology (traditional using $250 \mathrm{~L}$ wooden barrels versus alternative using micro-oxygenation and wood staves applied in $1000 \mathrm{~L}$ stainless steel tanks), the wood species used (chestnut and oak), and the ageing time (6,12, and 18 months). For this purpose, several features of the wine spirits were examined: chromatic characteristics resulting from the CIELab method, total phenolic index, concentrations of furfural, ellagic acid, vanillin, and coniferaldehyde, and total content of low molecular weight phenolic compounds determined by HPLC. FDA applied to spectral data highlighted the differentiation between all groups of samples, confirming the differentiation observed with the analytical parameters measured. All samples in the test set were differentiated and correctly assigned to the aged wine spirits by FDA. The FTIR-ATR spectroscopy combined with FDA is a powerful methodology to discriminate wine spirits resulting from different ageing technologies.
\end{abstract}

Keywords: FTIR-ATR; FDA; vector analysis; wine spirit; ageing technology; micro-oxygenation; wood; oak; chestnut; ageing time

\section{Introduction}

The contact of wine distillate with wood is recognised as a pivotal step of the aged wine spirit production, during which its quality increases and sensory fullness can be reached. Scientific evidence exists on the key role of several physicochemical phenomena, particularly the extraction and oxidation reactions involving the wood-derived compounds of low molecular weight, on the chemical changes (quantitative and qualitative aspects of the beverage's volatile and non-volatile composition) and sensory changes (colour, aroma, and taste) occurred [1-3]. Besides, they mainly depend on the ageing technology, the kind of wood used (oak and chestnut), and the length of the ageing process $[1,4,5]$. 
Despite the high-quality spirits attained by the traditional ageing technology, using wooden barrels, this expensive and lengthy process led to the search and study of sustainable alternative technologies. Research has been focused on a technology based on adding wood pieces to the distillate kept in stainless steel tanks, as for other alcoholic beverages [6,7]. Recently, the micro-oxygenation technique, reproducing the oxygen transfer that occurs in the wooden barrel, was applied to optimise this ageing technology. Promising outcomes based on the phenolic composition and colour of the wine spirits in the beginning of ageing were attained [8]. Nevertheless, a comprehensive approach is needed towards the full/robust characterisation of this novel technology, exploring the data acquired over the ageing period through different analytical and statistical methodologies.

Spectroscopic techniques are very useful for food and beverages quality evaluation because they require minimal or no sample preparation (absence of extraction, reactions with some other chemical species, treatment with a chelating agent, masking, sub-sampling, or other manipulation), they are rapid and non-destructive (causing no physicochemical changes during the analysis), and they can be used to simultaneously assess several parameters of a sample. In recent years, significant developments related to the applicability of vibrational spectroscopy combined with multivariate data analysis has been made to give the rapid quantification of several compounds in different matrices or to discriminate different groups of samples. Concerning the alcoholic beverages, the studies were more centred on other drinks than wine spirits. FTIR-ATR (Fourier transform infrared spectroscopy with Attenuated Total Reflection) was used to evaluate different parameter in alcoholic beverages, such as the determination of important quality parameters of beers [9], determination of ethanol content in liquors [10], quantitative analysis of methanol (an adulterant in alcoholic beverages) [11], analysis of ethanol and methanol content in traditional fruit spirits [12], and the authentication of whisky according to its botanical origin [13]. Actually, the studies on wine spirits with FTIR-ATR are scarce. One of them was carried out by Anjos et al. [14], applying the FTIR-ATR methodology to predict the alcoholic strength, methanol, acetaldehyde, and fusel alcohols contents of grape-derived spirits.

In this paper, a new application of functional data analysis (FDA) in the field of quality evaluation using spectroscopic techniques is presented. In recent years, FDA has been used in numerous investigations to analyse processes in continuous time; some examples are energy efficiency [15], medical research [16], econometrics [17], optimisation problems [18], industrial processes [19], environmental research [20,21], and food science [22]. In all these works, FDA showed its usefulness for the study of functions, defined in a specific interval, without missing the correlation between the observations.

FDA allows the analysis of the entire curves, which represent individual observations of the sample under study, detecting different behaviours throughout the curves [15,23]. Ordoñez et al. [23], in a similar context that this paper, showed significant reasons to analyse the sample with curves instead of individual observations. In addition, the contrast of similarity has been carried out from a vectorial approach, but summarising the curves with a single value; in this case, the mean. This is necessary because the curves, although representing individual data, are formed by a set of observations correlated to each other. Martínez et al. [20] explained how this correlation is not taken into account from a vectorial approach. Furthermore, from this point of view, to contrast the similarity between the samples, a classical analysis of variance (ANOVA) [24,25] and anon-parametric Kruskal's test [26] have been performed. Although this is a simpler approach, it contributes to highlight the strengths of FDA. On the one hand, Martínez et al. [15] presented how different conclusions can be reached for each approach because of the biased sample used in the vector analysis (mean of the curves) or different detection of outliers. On the other hand, among others, Sancho et al. [19] demonstrated that FDA presents more realistic and accurate results, showing how and at which specific part of the curve the groups have different spectrometric behaviours.

The aim of this research is to contrast the similarity between the samples obtained with FTIR-ATR spectrometry for wine spirits aged by different ageing technologies (traditional and alternative), with different kinds of wood (chestnut and oak) and over the ageing period (6,12, and 18 months), using functional data analysis of variance (FANOVA). 
Thus, the second section presents, on the one hand, the data used in this study and, on the other hand, the specific methodology applied to obtain the results. The third section presents the results of the comparison and analysis of the differences between the wine spirit samples. Then, in the fourth section, a discussion is carried out about the results and the information obtained with them. Finally, in Section 5, the conclusions of this work are presented.

\section{Materials and Methods}

\subsection{Samples}

A total of 30 samples of wine spirit (produced at industrial scale) aged with Limousinoak (Quercus robur L.) and Portuguese chestnut (Castanea sativa Mill.) for 6, 12, and 18 months of ageing time were analysed (Figure 1), covering the following categories:

- $\quad$ TL-aged in $250 \mathrm{~L}$ new oak wooden barrels;

- $\quad$ TC-aged in $250 \mathrm{~L}$ new chestnut wooden barrels;

- $\quad \mathrm{AL}$-aged in $1000 \mathrm{~L}$ stainless steel tanks with oak wood staves and micro-oxygenation;

- AC-aged in $1000 \mathrm{~L}$ stainless steel tanks with chestnut wood staves and micro-oxygenation.

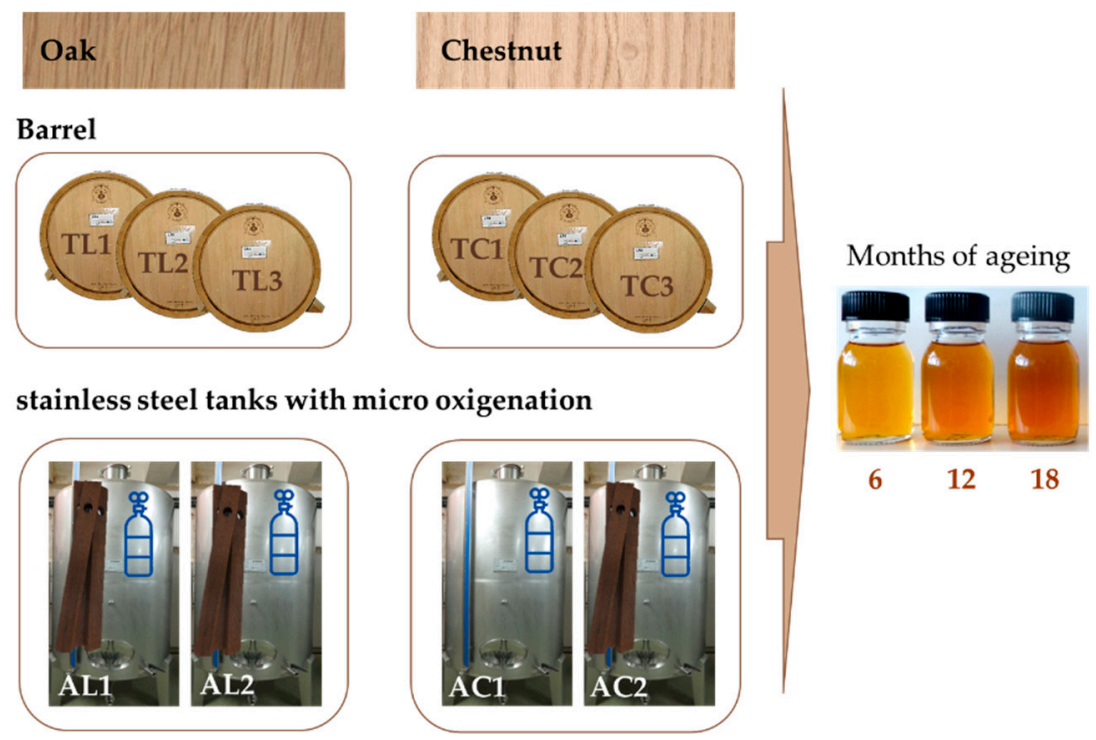

Figure 1. Scheme of the essay. 1, 2, and 3 indicate the essay replicates.

From each sample, four independent samples were taken for spectral analysis, totalising 120 spectra analysed.

The wooden barrels and the stainless-steel tanks were placed in the cellar in similar environmental conditions. The same wine distillate (alcohol strength, $77.4 v / v ; \mathrm{pH}, 5.44$; total acidity, as acetic acid, $0.13 \mathrm{~g} / \mathrm{hL}$ of absolute ethanol; volatile acidity, as acetic acid, $0.11 \mathrm{~g} / \mathrm{hL}$ of absolute ethanol) produced by the Adega Cooperativa da Lourinhã, Portugal, was used. The wood pieces and barrels were manufactured by J.M. Gonçalves cooperage (Palaçoulo, Portugal) with the medium plus toasting level, as described by Canas et al. [8].

To characterise the wine spirits aged by different technologies, with different wood species, through the ageing time, several analytical determinations were performed for all the samples: CIELAB colour parameters (lightness, saturation, and chromaticity coordinates), total phenolic index, and low molecular weight compounds contents, according to the methodologies described below. All the analyses were done in duplicate. 


\subsection{Analytical Procedures}

\subsubsection{Analysis of Chromatic Characteristics}

The chromatic characteristics of the wine spirits-lightness $\left(\mathrm{L}^{*}\right.$ ), varying between $100 \%$ (fully transparent) and $0 \%$ (fully opaque); saturation $\left(C^{*}\right)$; chromaticity coordinates ( ${ }^{*}$ and $b^{*}$ ), of which the coordinate $a^{*}$ varies between green $\left(a^{*}<0\right)$ and red hues $\left(a^{*}>0\right)$, and the coordinate $b^{*}$ varies between blue $\left(b^{*}<0\right)$ and yellow hues $\left(b^{*}>0\right)$-were analysed according to the CIELab method. The analysis was performed in a Varian Cary 100 Bio spectrophotometer (Santa Clara, CA, USA) with a $10 \mathrm{~mm}$ glass cell, considering a D65 illuminant and a $10^{\circ}$ standard observer. The transmittance measurement was made every $10 \mathrm{~nm}$ from 380 to $770 \mathrm{~nm}$. The analysis was performed in duplicate.

\subsubsection{Determination of the Total Phenolic Index}

The total phenolic index (TPI) of the wine spirits was analysed as described by Cetó et al. [27]: dilution of the samples with ethanol/water 77:23 v/v; absorbance measurement at $280 \mathrm{~nm}$, using a Varian Cary 100 Bio spectrophotometer (Santa Clara, CA, USA) with a $10 \mathrm{~mm}$ quartz cell; calculation of the total phenolic index by multiplying the measured absorbance by the dilution factor. The analysis was performed in duplicate.

\subsubsection{Analysis of Low Molecular Weight Compounds}

The phenolic and furanic compounds, namelyphenolic acids (gallic acid, vanillic acid, syringic acid and ellagic acid), phenolic aldehydes (vanillin, syringaldehyde, coniferaldehyde, and sinapaldehyde), coumarins (umbelliferone and scopoletin), and furanic aldehydes (5-hydroxymethylfurfural, 5-methylfurfural, and furfural) were quantified by liquid chromatography according to the method proposed by Canas et al. [28]. All compounds were quantified to calculate the total content of low molecular weight compounds. Only some compounds-furfural, ellagic acid, vanillin, and coniferaldehyde-were considered in the discussion of individual compounds contents based on their highly discriminant power.

The chromatographic analysis was carried out in a HPLC Lachrom Merck Hitachi system (Merck, Darmstadt, Germany) composed of a quaternary pump L-7100, a column oven L-7350 equipped with a $250 \mathrm{~mm} \times 4 \mathrm{~mm}$ i.d. LiChrospher RP $18(5 \mu \mathrm{m})$ column (Merck, Darmstadt, Germany), a UV-Vis detector L-7400, a fluorescence detector L-7480 (connected to the UV-Vis detector), and an autosampler L-7250. The HSM D-7000 software (Merck, Darmstadt, Germany) was used for the management, acquisition, and treatment of the data. The following chromatographic conditions were used: (i) binary gradient consisting of solvent $\mathrm{A}$, water: formic acid $(98: 2 \mathrm{v} / \mathrm{v})$ and solvent $\mathrm{B}$, methanol:water:formic acid (70:28:2 v/v/v) as follows: $0 \%$ isocratic B in $3 \mathrm{~min}$, linear gradient from $0 \%$ to $40 \%$ B in $22 \mathrm{~min}$, from $40 \%$ to $60 \%$ B in $18 \mathrm{~min}, 60 \%$ isocratic B in $12 \mathrm{~min}$, linear gradient from $60 \%$ to $80 \%$ B in $5 \mathrm{~min}$, $80 \%$ isocratic B in $5 \mathrm{~min}$; (ii) column temperature of $40{ }^{\circ} \mathrm{C}$; (iii) flow rate of $1 \mathrm{~mL} / \mathrm{min}$. Phenolic acids and furanic aldehydes were detected at $280 \mathrm{~nm}$, phenolic aldehydes were detected at $320 \mathrm{~nm}$, and coumarins were detected at $325 \mathrm{~nm}$ (excitation)/454 nm (emission).

Samples were added with an internal standard $(20 \mathrm{mg} / \mathrm{L}$ of 4-hydroxybenzaldehyde), filtered through $0.45 \mu \mathrm{m}$ membrane (Titan, Scientific Resources Ltd., Gloucester, UK) and analysed by the direct injection of $20 \mu \mathrm{L}$. The identification of chromatographic peaks was made through comparison of their retention time and UV-Vis spectra with those commercial standards. The assessment of chromatographic purity of the peaks and their UV-Vis spectra $(200-400 \mathrm{~nm})$ were performed in Waters system composed of a photodiode-array detector (Waters 996), in the same chromatographic conditions and managed by 'Millennium 2010' software (Waters, Milford, NA, USA). The analysis was performed in duplicate. The quantification of each compound was based on a calibration curve made with the corresponding commercial standard. 


\subsubsection{Spectroscopic Analyses}

Spectra were acquired by the Fourier transform infrared spectroscopic method with platinum Attenuated Total Reflectance (FTIR-ATR) with a Bruker spectrometer (Alpha, Bruker Optic GmbH, Ettlingen, Germany) using a diamond crystal. Four spectra per sample were obtained with 128 scans per spectrum at a spectral resolution of $8 \mathrm{~cm}^{-1}$ in the range of 4000 to $450 \mathrm{~cm}^{-1}$.

The FTIR-ATR used was equipped with a flow-through cell with controlled temperature. The cleaning of the cell was done by the injection of water in the flow-through cell, and the background was also measured with distilled water.

\subsection{Statistical Analysis}

\subsubsection{Statistical Treatment of Analytical Data}

A two-way analysis of variance (ANOVA) was carried out to examine the influence of the two fixed factors-ageing technology (two levels: alternative versus traditional) and kind of wood (two levels: Limousin oak versus chestnut)—on the chromatic characteristics, total phenolic index, and low molecular weight compounds' contents of the wine spirits after 6,12 , and 18 months of ageing. For each significant factor or interaction, the variance percentage was calculated. Fisher's least significant difference (LSD) test was used to compare the average values observed for each sample group. All the calculations were carried out using Statistica vs. 5 (Statsoft Inc., Tulsa, OK, USA).

\subsubsection{Functional Analysis}

The similarity between the different samples of ageing technology and the different samples of ageing time was contrasted. This analysis was carried out from a vectorial and functional approach. Vectorially, the tests used were the classical ANOVA [25], comparing the mean levels of the groups, and Kruskal's non-parametric test [26], which studies whether the observations of each group come from the same distribution. In addition, from the functional approach, the functional ANOVA (FANOVA) was performed.

Functional Data Analysis (FDA)

The analyses from a functional approach study functions, based on sets of observations, were defined in a determined interval $\mathrm{I}=[\mathrm{a}, \mathrm{b}]$. One of its strengths is its structure of infinite dimensions that allows to extend the possibilities of data analysis $[29,30]$. A random variable, measured at a set of discrete points $\left\{t_{g}\right\}_{g=1}^{G} \in[a, b]$, has to take values in metric or semi-metric spaces to be considered functional. Thus, functional data take the form of a matrix with $n$ rows, one for each individual studied, and $G$ columns representing the points of evaluation of the functions [31,32].

Smoothing is the most used process to convert discrete observations into continuous functions, $x(t), t \in \mathcal{X} \subset \mathcal{F}$; where $\mathcal{F}$ is the functional space. Specifically, assuming that the functions are observed with error, a functional basis expansion can be adopted as follows:

$$
x(t)=\sum_{w=1}^{W} c_{w} \phi_{w}(t)
$$

where $\left\{c_{w}\right\}_{w=1}^{W}$ is the $w$-th basis coefficients, $\left\{\phi_{w}(t)\right\}_{w=1}^{W}$ is the $w$-th basis function, and $W$ is the number of basis functions under consideration [29,32]. Thus, the basis functions used in this work were splines [33] due to their specific properties such as the possibility of generating large basis sets easily or their flexibility [34]. On the other hand, to select the number of bases of each sample, the determination coefficient $R^{2}$ was taken into account. The number of bases is the minimum number at which $R^{2}$ 
stops improving significantly or surpasses the value of 0.99 (see Martínez et al. [15]). Moreover, the smoothing process involves solving the following problem:

$$
\min _{x \in F} \sum_{g=1}^{G}\left\{z_{g}-x\left(t_{g}\right)\right\}^{2}+\lambda \Gamma(x)
$$

where $z_{g}=x\left(t_{g}\right)+\epsilon_{g}$ is the value obtained by evaluating $x$ at point $t_{g}$ with $\epsilon_{g}$ being a random noise with zero mean, $\lambda$ is a parameter controlling the intensity of regularisations, and $\Gamma$ is a parameter that makes it costly to reach complex solutions. Then, the basis coefficients can be expressed as the solution of the smoothing process as follows [29,35]:

$$
c=\left(\boldsymbol{\Phi}^{t} \boldsymbol{\Phi}+\lambda \mathbf{R}\right)^{-1} \boldsymbol{\Phi}^{T} \mathbf{z}
$$

being $\boldsymbol{\Phi}$ a $G x W$ matrix formed by $\Phi_{g w}=\phi_{w}\left(t_{g}\right)$ and $\mathbf{R}$ being a $W x W$ matrix of the elements $\mathbf{R}_{w g}=\int_{T} D^{2} \phi_{w}(t) D^{2} \phi_{g}(t) d t$ where $D^{n} \phi_{w}(t)$ is the $n$ th-order differential operator of $\phi_{w}$.

\section{Functional Depths}

The depth concept, in classical multivariate statistics, was used to measure the centrality of a point $x \in \mathbb{R}^{d}$ within a data set. The points nearest to the centre obtain a higher depth value [36]. With a functional approach, depths measure the centrality of a curve in relation to the other curves of the sample $x_{1}, \ldots, x_{n}$, coming from a stochastic process $\mathcal{X}(\cdot)$ evaluated at a specific interval $[a, b] \in \mathbb{R}[37,38]$.

Although there exist different functional types of depths (Fraiman-Muniz [37], h-modal [39] or Random Projections [38]), the most widely used is the h-modal depth due to its better performance in the correct detection of outliers [36]. Therefore, the functional mode of the sample will be the curve most densely surrounded by other curves. The functional depth of a certain curve in a specific sample is calculated as follows:

$$
M D_{n}\left(x_{i}, h\right)=\sum_{w=1}^{n} K\left(\frac{\left\|x_{i}-x_{w}\right\|}{h}\right)
$$

where $\|\cdot\|$ is the norm in a functional space, $K: \mathbb{R}^{+} \rightarrow \mathbb{R}^{+}$is a kernel function, and $h$ represents the bandwidth parameter [39].

Functional depths, which are considered as a measure of dispersion, are essential in the detection of outliers. In any data analysis, the identification of these atypical data is crucial because they could affect the subsequent estimations. In addition, examining them is important to discover the causes that give these observations a different behaviour from the rest. Besides, in functional analyses, it is even more important because it is possible that individually, the values that form the curve are not outliers in a vectorial way but, from a functional point of view, the entire curve could be [36,40]. Martínez et al. [29] explained in detail how to detect functional outliers within a functional sample.

\section{Functional ANOVA (FANOVA)}

Functional data Analysis of Variance, similar to the vector version, contrasts the distance between the mean levels of the factor variables. The aim of this contrast is to find out if the set of functions studied are statistically distinguishable [41]. There will also be $Q$ independent samples $X_{g j}(t), j=1, \ldots, n_{g}$; $t \in I=[a, b]$. But these samples are extracted from $\mathcal{L}^{2}(l)$ processes $X_{g}(t), g=1, \ldots, Q$ and their mean function is $E\left(X_{g}(t)\right)=m_{g}(t)[42,43]$. If the functional sample is divided into groups like $\left\{\mathcal{X}_{j}, \mathcal{A}_{j}\right\}_{j=1}^{n} \in \mathcal{F}$ $\mathrm{x} \mathcal{A}=\{1, \ldots, A\}$, being $\mathcal{A}$ the factor variable, the hypothesis contrast has the following form:

$$
\left\{\begin{array}{l}
H_{0}: \bar{X}_{1}(t)=\bar{X}_{2}(t)=\ldots=\bar{X}_{A}(t) \\
H_{1}: \exists h, e \text { s.t. } \bar{X}_{h}(t) \neq \bar{X}_{e}(t)
\end{array}\right.
$$


The model for the $j$-th observation belonging to the $g$-th group has the following form [41]:

$$
X_{j g}(t)=\bar{X}(t)+\alpha_{g}(t)+\epsilon_{j g}(t)
$$

where $X_{j g}(t)$ is the functional value ofgroup $g, \alpha_{g}(t)$ is the effect of being part of a determined group and $\epsilon_{j g}(t)$ represents the unexplained variability for the $i$-th observation of group $g$.Furthermore, the model in Equation (6) can be represented in its matrix notation:

$$
\mathbf{X}(t)=\mathbf{Z} \boldsymbol{\gamma}(t)+\epsilon(t)
$$

being $\mathbf{X}(t)$ a N-dimensional vector, $\gamma(t)=\left(\bar{X}(t), \alpha_{1}(t), \ldots, \alpha_{Q}(t)\right)^{T}$ a $(\mathrm{Q}+1)$-dimensional vector, $\epsilon(t)$ a vector of $\mathrm{N}$ residual functions, and $\mathrm{Z}$ the design matrix with dimension $(\mathrm{N}, \mathrm{Q}+1)$.

Thus, to assure the indentification of the functional effects $\alpha_{g}(t)$, the sum to zero constraint is introduced [41,44]:

$$
\sum_{g=2}^{Q+1} \gamma(t)=0, \forall t
$$

The parameter vector $\gamma(t)$ in Equation (7) can be estimated minimising the standard least squares:

$$
\operatorname{LMSSE}(\boldsymbol{\gamma})=\int[\mathbf{X}(t)-\mathbf{Z} \boldsymbol{\gamma}(t)]^{T}[\mathbf{X}(t)-\mathbf{Z} \boldsymbol{\gamma}(t)] d t
$$

subject to the constraint (8) [41,44].

Regarding the contrast in Equation (5), most tests are based on F test statistic [32,45]:

$$
F_{n}(t)=\frac{\operatorname{SSR}_{n}(t) /(Q-1)}{\operatorname{SSE}_{n}(t) /(n-Q)}
$$

where

$$
\begin{gathered}
\operatorname{SSR}_{n}(t)=\sum_{g=1}^{Q} n_{g}\left(\bar{X}_{g}(t)-\bar{X}(t)\right)^{2} \\
\operatorname{SSE}_{n}(t)=\sum_{g=1}^{Q} \sum_{j=1}^{n_{g}}\left(X_{g j}(t)-\bar{X}_{g}(t)\right)^{2}
\end{gathered}
$$

represents the variations between groups and within groups, respectively. In addition, for these calculations, the sample mean function $\bar{X}(t)=(1 / n) \sum_{g=1}^{Q} \sum_{j=1}^{n_{g}} X_{g j}(t)$ and the sample group mean function $\bar{X}_{g}(t)=\left(1 / n_{g}\right) \sum_{j=1}^{n_{g}} X_{g j}(t), g=1, \ldots, Q$ were taken into account.

In this work, two specific tests were used to contrast the similarity between samples. On the one hand, the $\mathrm{F}$ test with the reduced bias estimation method (FB) [46]. This test uses both point variations between groups and variations within groups. Specifically, the test statistic has the form:

$$
F_{n}=\frac{\int_{Q} S S R_{n}(t) d t /(Q-1)}{\int_{Q} S S E_{n}(t) /(n-Q)}
$$

The distribution of this statistic is approximated by $F_{(Q-1) k,(n-Q) k}$, where $\mathrm{k}$ is estimated by the bias-reduced method. The $p$-value taken into account comes from $P\left(F_{(Q-1) k,(n-Q) k}>F_{n}\right)[45,46]$.

On other hand, a permutation test based on a representation of the base function (FP) was used. This test is based on the basis representation procedure presented by Górecki and Smaga [47]. 
The functional observations are be represented by a finite number of basis functions $\varphi_{m} \in \mathcal{L}^{2}(I)$, $m=1, \ldots, K$ as follows:

$$
X_{g j}(t) \approx \sum_{m=1}^{K} c_{g j m} \varphi_{m}(t), t \in I
$$

where $c_{g j m}$ are random variables with a significantly large $K$. Moreover, this test uses the following approximation of Equation (9) [45]:

$$
\frac{(a-b) /(Q-1)}{(c-a) /(n-Q)}
$$

where

$$
\begin{gathered}
a=\sum_{g=1}^{Q} \frac{1}{n_{g}} 1_{n_{g}}^{T} \mathbf{C}_{g}^{T} \mathbf{J}_{\varphi} \mathbf{C}_{g} 1_{n_{g}} \\
b=\frac{1}{n} \sum_{g=1}^{Q} \sum_{j=1}^{Q} 1_{n_{g}}^{T} \mathbf{C}_{g}^{T} \mathbf{J}_{\varphi} \mathbf{C}_{j} 1_{n_{j}} \\
c=\sum_{g=1}^{Q} \operatorname{trace}\left(\mathbf{C}_{g}^{T} \mathbf{J}_{\varphi} \mathbf{C}_{g}\right)
\end{gathered}
$$

being $1_{a}$ a vector of ones with dimension $a x 1, \mathbf{C}_{g}=\left(c_{g j m}\right)_{j=1, \ldots, n_{g} ; m=1, \ldots, K^{\prime}} i=1, \ldots, Q$, and $\mathbf{J}_{\varphi}:=\int_{I} \boldsymbol{\varphi}(t) \boldsymbol{\varphi}^{T}(t) d t$ is the matrix of cross-products with dimensions $K x K$ based on $\boldsymbol{\varphi}(\mathbf{t})=$ $\left(\varphi_{1}(t), \ldots, \varphi_{K}(t)\right)^{T}$.

\section{Results}

The two-way ANOVA results (Table 1) show that the ageing technology and the kind of wood had a highly significant effect on the colour and total phenolic content acquired by the wine spirits during the ageing process (after 6, 12, and 18 months). Among these factors, greater influence was exerted by the ageing technology (higher percentage of the variance explained) on the chromatic characteristics, while a similar weight of both factors was observed in the phenolic content. Regardless of the sampling time, the wine spirits aged with micro-oxygenation and chestnut wood staves (AC) exhibited a significantly lower value of lightness $\left(L^{*}\right)$ and significantly higher values of saturation $\left(C^{*}\right)$ and chromaticity coordinates $\left(\mathrm{a}^{*}\right.$ and $\mathrm{b}^{*}$ ) than the others. This set of chromatic characteristics reflects a more evolved colour, since lower $\mathrm{L}^{*}$ and higher $\mathrm{C}^{*}$ correspond to a more intense/darker colour, and the combination of higher $\mathrm{a}^{*}$ and $\mathrm{b}$ * (yellow and red hues, respectively) is associated with a greater intensity of amber or orange hue, which made these spirits look older than the others. The colour of wine spirits from Limousin wooden barrels (TL) was on the opposite side, while the wine spirits aged with micro-oxygenation and Limousin wood staves (AL) and those aged in chestnut wooden barrels (TC) presented intermediate characteristics. 
Table 1. Effect of the ageing technology and kind of wood on the chromatic characteristics and total phenolic index acquired by the wine spirits after 6,12 , and 18 months of ageing. AC: Alternative Chestnut, AL: Alternative Oak, TC: Traditional Chestnut, TL: Traditional Oak.

\begin{tabular}{|c|c|c|c|c|c|c|}
\hline $\begin{array}{l}\text { Ageing } \\
\text { Months }\end{array}$ & Code & $L^{*}(\%)$ & A * & B * & $C^{*}$ & TPI \\
\hline \multirow{4}{*}{6} & $\mathrm{TC}$ & $85.41 \pm 1.41^{b}$ & $3.37 \pm 1.08^{b}$ & $50.96 \pm 2.68^{b}$ & $51.08 \pm 2.74^{b}$ & $24.94 \pm 1.98^{b}$ \\
\hline & $\mathrm{TL}$ & $93.73 \pm 0.42^{c}$ & $-1.25 \pm 0.17^{\mathrm{a}}$ & $26.76 \pm 2.21^{a}$ & $26.79 \pm 2.20^{a}$ & $11.99 \pm 1.18^{a}$ \\
\hline & $\mathrm{AC}$ & $77.14 \pm 1.26^{\mathrm{a}}$ & $11.79 \pm 1.22^{\mathrm{c}}$ & $70.00 \pm 1.59^{c}$ & $70.99 \pm 1.77^{c}$ & $47.79 \pm 3.80^{c}$ \\
\hline & $\mathrm{AL}$ & $87.55 \pm 0.23^{b}$ & $1.75 \pm 0.14^{b}$ & $46.24 \pm 0.14^{b}$ & $46.27 \pm 0.15^{b}$ & $26.88 \pm 0.87^{b}$ \\
\hline \multirow{4}{*}{$\begin{array}{l}\text { Variance } \\
\text { origin }\end{array}$} & Technology (S) & $61.9^{* * *}$ & $52.7^{* * *}$ & $60.2^{* * *}$ & $60.2 * * *$ & $42.1 * * *$ \\
\hline & Wood (W) & $36.7^{* * *}$ & $31.9^{* * *}$ & $38.8^{* * *}$ & $38.8^{* * *}$ & $52.4^{* * *}$ \\
\hline & SxW & NS & $14.0 * *$ & NS & NS & $4.2^{*}$ \\
\hline & Residual & 1.5 & 1.3 & 1.0 & 1.0 & 1.3 \\
\hline \multirow{4}{*}{12} & $\mathrm{TC}$ & $79.11 \pm 1.38^{b}$ & $9.89 \pm 1.31^{b}$ & $69.41 \pm 1.64^{b}$ & $70.11 \pm 1.80^{b}$ & $37.90 \pm 1.94^{b}$ \\
\hline & $\mathrm{TL}$ & $90.62 \pm 1.04^{c}$ & $-0.49 \pm 0.65^{a}$ & $40.66 \pm 3.4^{\mathrm{a}}$ & $40.67 \pm 3.40^{\mathrm{a}}$ & $17.55 \pm 1.81^{\mathrm{a}}$ \\
\hline & $\mathrm{AC}$ & $65.58 \pm 1.97^{\mathrm{a}}$ & $25.63 \pm 1.78^{c}$ & $87.25 \pm 0.56^{c}$ & $90.95 \pm 1.04^{\mathrm{c}}$ & $65.72 \pm 1.37^{c}$ \\
\hline & $\mathrm{AL}$ & $79.17 \pm 0.60^{b}$ & $10.38 \pm 0.53^{b}$ & $70.87 \pm 0.61^{b}$ & $71.63 \pm 0.68^{b}$ & $37.86 \pm 0.23^{b}$ \\
\hline \multirow{4}{*}{$\begin{array}{l}\text { Variance } \\
\text { origin }\end{array}$} & Technology (S) & $49.2^{* * *}$ & $49.9^{* * *}$ & $49.4^{* * *}$ & $50.7^{* * *}$ & $48.6^{* * *}$ \\
\hline & Wood (W) & $49.7^{* * *}$ & $46.3^{* * *}$ & $43.5^{* * *}$ & $44.9^{* * *}$ & $48.8^{* * *}$ \\
\hline & SxW & NS & $3.1 *$ & $6.2 * * *$ & $3.6 *$ & $2.2 *$ \\
\hline & Residual & 1.1 & 0.8 & 0.9 & 0.8 & 0.5 \\
\hline \multirow{4}{*}{18} & TC & $77.33 \pm 1.25^{b}$ & $12.06 \pm 1.24^{b}$ & $73.97 \pm 1.22^{b}$ & $74.95 \pm 1.40^{b}$ & $40.98 \pm 2.46^{b}$ \\
\hline & $\mathrm{TL}$ & $89.61 \pm 1.17^{c}$ & $-0.02 \pm 0.84^{\mathrm{a}}$ & $44.35 \pm 3.74^{\mathrm{a}}$ & $44.36 \pm 3.74^{\mathrm{a}}$ & $18.15 \pm 1.63^{a}$ \\
\hline & $\mathrm{AC}$ & $62.29 \pm 1.94^{\mathrm{a}}$ & $28.97 \pm 1.62^{c}$ & $89.27 \pm 0.12^{c}$ & $93.86 \pm 0.61^{c}$ & $71.60 \pm 2.50^{c}$ \\
\hline & $\mathrm{AL}$ & $76.59 \pm 0.52^{b}$ & $13.19 \pm 0.45^{b}$ & $75.87 \pm 0.44^{b}$ & $77.01 \pm 0.51^{b}$ & $40.55 \pm 1.25^{b}$ \\
\hline \multirow{4}{*}{$\begin{array}{c}\text { Variance } \\
\text { origin }\end{array}$} & Technology (S) & $52.2 * * *$ & $52.9^{* * *}$ & $47.7^{* * *}$ & $50.0 * * *$ & $47.9^{* * *}$ \\
\hline & Wood (W) & $46.9^{* * *}$ & $45.2^{* * *}$ & $40.2^{* * *}$ & $42.3^{* * *}$ & $49.5^{* * *}$ \\
\hline & SxW & NS & $1.4^{*}$ & $11.1^{* *}$ & $6.8^{* * *}$ & $2.1^{*}$ \\
\hline & Residual & 0.9 & 0.6 & 0.9 & 0.9 & 0.6 \\
\hline
\end{tabular}

$\mathrm{L} *$ - lightness; $\mathrm{a} * \mathrm{~b} *$ - chromaticity coordinates; $\mathrm{C} *$-saturation; TPI—total phenolic index. For each sampling time $(6,12$ and 18 months), mean values with the same letter in a column are not statistically different. NS, $p>0.05$; ${ }^{*} 0.01<p<0.05 ;{ }^{* *} 0.001<p<0.01 ; * * * 0.001$.

In a previous work, this research team have already identified furfural, ellagic acid, vanillin and coniferaldehyde as markers of the ageing technology and the kind of wood used [8]. The results obtained for these compounds are shown in Table 2. It should be stressed that most of the low molecular weight compounds contents were mainly dependent on the ageing technology (higher percentage of the variance explained), as aforementioned for the chromatic characteristics and TPI, but ellagic acid content was closely related to the kind of wood. Indeed, significantly higher levels of furfural, vanillin, and coniferaldehyde were found in the wine spirits aged by the alternative technology; the first two were higher in the modality comprising chestnut wood staves $(\mathrm{AC})$, whereas the latter was higher in the modality comprising Limousin wood staves (AL). Slight differences were found between the wine spirits from chestnut barrels (TC) and Limousin oak barrels (TL). Regarding ellagic acid, higher content was promoted by the chestnut wood (AC and TC), especially in the alternative technology. The contact with Limousin oak together with micro-oxygenation (AL) induced a slightly lower content of this phenolic acid, and a weak performance was showed by the Limousin oak barrels (TC).

Besides the differences between the two ageing technologies and the two kinds of wood, the results also reveal a remarkable role of the ageing time, as indicated by the percentage of variance observed for each factor in ANOVA (Table 2). Regardless of the ageing modality, there was a gradual decrease of lightness and a gradual increase of saturation and chromatic coordinates that correspond to the colour development over the ageing process. 
Table 2. Effect of the ageing technology and kind of wood on the contents of low molecular weight compounds (mg/L absolute ethanol) of the wine spirits after 6, 12, and 18 months of ageing.

\begin{tabular}{|c|c|c|c|c|c|c|}
\hline $\begin{array}{l}\text { Ageing } \\
\text { Months }\end{array}$ & Code & Furfural & Ellagic Acid & Vanillin & Coniferaldehyde & sumHPLC \\
\hline \multirow{4}{*}{6} & $\mathrm{TC}$ & $38.31 \pm 6.90^{\mathrm{a}}$ & $8.12 \pm 1.41^{b}$ & $2.03 \pm 0.01^{b}$ & $6.17 \pm 0.63^{a}$ & $163.10 \pm 24.08^{b}$ \\
\hline & $\mathrm{TL}$ & $31.73 \pm 6.38^{\mathrm{a}}$ & $3.43 \pm 0.20^{\mathrm{a}}$ & $1.49 \pm 0.08^{a}$ & $5.21 \pm 0.04^{\mathrm{a}}$ & $78.99 \pm 9.71^{\mathrm{a}}$ \\
\hline & $\mathrm{AC}$ & $127.05 \pm 5.07^{c}$ & $15.35 \pm 0.38^{c}$ & $4.62 \pm 0.20^{\mathrm{d}}$ & $10.60 \pm 0.65^{b}$ & $296.05 \pm 15.91^{c}$ \\
\hline & $\mathrm{AL}$ & $87.74 \pm 4.11^{\mathrm{b}}$ & $6.28 \pm 0.70^{a, b}$ & $3.26 \pm 0.16^{c}$ & $12.20 \pm 0.52^{b}$ & $195.23 \pm 3.04^{b}$ \\
\hline \multirow{4}{*}{$\begin{array}{l}\text { Variance } \\
\text { origin }\end{array}$} & Technology(S) & $82.7^{* * *}$ & $30.4^{* * *}$ & $79.1^{* * *}$ & $98.5^{* * *}$ & $63.1^{* * *}$ \\
\hline & Wood(W) & $8.1^{* *}$ & $56.9^{* * *}$ & $15.1^{* * *}$ & NS & $34.6^{* * *}$ \\
\hline & SxW & $8.0 * * *$ & $10.8^{* * *}$ & $5.3^{* *}$ & NS & NS \\
\hline & Residual & 1.2 & 2.0 & 0.5 & 1.5 & 2.3 \\
\hline \multirow{4}{*}{12} & TC & $35.85 \pm 6.03^{a}$ & $12.86 \pm 1.16^{b}$ & $3.61 \pm 0.22^{b}$ & $7.00 \pm 0.57^{\mathrm{a}}$ & $231.68 \pm 26.34^{b}$ \\
\hline & TL & $31.36 \pm 5.80^{\mathrm{a}}$ & $5.64 \pm 0.34^{\mathrm{a}}$ & $2.66 \pm 0.23^{\mathrm{a}}$ & $6.49 \pm 0.58^{\mathrm{a}}$ & $95.09 \pm 13.67^{\mathrm{a}}$ \\
\hline & $\mathrm{AC}$ & $131.17 \pm 4.91^{\mathrm{c}}$ & $24.89 \pm 1.26^{c}$ & $8.68 \pm 0.02^{d}$ & $13.97 \pm 0.17^{b}$ & $369.24 \pm 8.57^{d}$ \\
\hline & $\mathrm{AL}$ & $96.08 \pm 1.93^{b}$ & $11.94 \pm 0.88^{b}$ & $6.77 \pm 0.09^{c}$ & $19.61 \pm 0.41^{c}$ & $275.32 \pm 4.56^{c}$ \\
\hline \multirow{4}{*}{$\begin{array}{l}\text { Variance } \\
\text { origin }\end{array}$} & Technology(S) & $87.9^{* * *}$ & $41.3^{* * *}$ & $89.2 * * *$ & $79.7^{* * *}$ & $64.5^{* * *}$ \\
\hline & Wood(W) & $5.2 * *$ & $50.0^{* * *}$ & $8.6^{* * *}$ & $5.1^{* * *}$ & $33.8^{* * *}$ \\
\hline & SxW & $6.1^{* * *}$ & $7.8 * * *$ & $1.8^{* * *}$ & $14.8^{* * *}$ & NS \\
\hline & Residual & 0.8 & 0.9 & 0.3 & 0.4 & 1.7 \\
\hline \multirow{4}{*}{18} & TC & $36.55 \pm 7.28^{a}$ & $15.48 \pm 1.41^{b}$ & $4.43 \pm 0.34^{b}$ & $6.85 \pm 0.75^{a}$ & $271.85 \pm 38.84^{b}$ \\
\hline & $\mathrm{TL}$ & $31.63 \pm 6.26^{\mathrm{a}}$ & $6.81 \pm 0.49^{a}$ & $3.13 \pm 0.23^{a}$ & $6.41 \pm 0.60^{\mathrm{a}}$ & $104.10 \pm 16.10^{\mathrm{a}}$ \\
\hline & $\mathrm{AC}$ & $113.35 \pm 4.27^{c}$ & $28.17 \pm 1.15^{c}$ & $8.61 \pm 0.07^{\mathrm{d}}$ & $11.16 \pm 0.15^{b}$ & $347.46 \pm 4.33^{c}$ \\
\hline & $\mathrm{AL}$ & $86.72 \pm 0.21^{b}$ & $13.81 \pm 0.23^{b}$ & $7.49 \pm 0.24^{c}$ & $17.93 \pm 0.07^{c}$ & $275.63 \pm 4.79^{b}$ \\
\hline \multirow{4}{*}{$\begin{array}{c}\text { Variance } \\
\text { origin }\end{array}$} & Technology(S) & $89.4^{* * *}$ & $39.1 * * *$ & $92.0 * * *$ & $63.3^{* * *}$ & $43.6^{* * *}$ \\
\hline & Wood $(W)$ & $4.8^{* * *}$ & $53.7^{* * *}$ & $7.2 * * *$ & $10.0^{* * *}$ & $40.9^{* * *}$ \\
\hline & SxW & $4.3^{*}$ & $6.2 * * *$ & NS & $26.0^{* * *}$ & $11.9 *$ \\
\hline & Residual & 1.5 & 0.8 & 0.7 & 0.7 & 3.6 \\
\hline
\end{tabular}

Furf-furfural; Ellag—ellagic acid; Vanil—vanillin; Cofde—coniferaldehyde; sumHPLC—-total content of low molecular weight compounds determined by HPLC. For each sampling time $(6,12$, and 18 months), mean values with the same letter in a column are not. NS, $p>0.05 ;{ }^{*} 0.01<p<0.05 ;{ }^{* *} 0.001<p<0.01$; ${ }^{* * *} p<0.001$.

The levels of significance shown in Table 3 reveal that the variation of chromatic characteristics, phenolic content (TPI and sumHPLC), and most of individual compounds contents were mostly significant between 6 months and 12 months. Significant differences between the three sampling times marked the wine spirits aged by the alternative technology with Limousin staves. In general, the L * parameter decreased over the ageing time, while the other parameters $\left(a^{*}, b^{*}\right.$, and $\left.C^{*}\right)$ increased. Furfural, ellagic acid, vanillin, coniferaldehyde and total content of low molecular weight compounds increased. Similar results were observed in the first months of ageing time of this kind of wine spirit [8].

Table 3. Differences observed for each samples group (technology vs. wood) during the ageing time.

\begin{tabular}{|c|c|c|c|c|c|c|c|c|c|c|c|c|}
\hline & \multicolumn{3}{|c|}{ TC } & \multicolumn{3}{|c|}{ TL } & \multicolumn{3}{|c|}{$\mathrm{AC}$} & \multicolumn{3}{|c|}{ AL } \\
\hline & 6 & 12 & 18 & 6 & 12 & 18 & 6 & 12 & 18 & 6 & 12 & 18 \\
\hline$L^{*}(\%)$ & $\mathrm{b}$ & $\mathrm{a}$ & $\mathrm{a}$ & $b$ & $\mathrm{a}$ & $\mathrm{a}$ & $\mathrm{b}$ & $\mathrm{a}$ & $\mathrm{a}$ & c & $\mathrm{b}$ & $\mathrm{a}$ \\
\hline$a^{*}$ & a & $\mathrm{b}$ & $\mathrm{b}$ & $\mathrm{a}$ & $\mathrm{a}$ & $\mathrm{a}$ & $\mathrm{a}$ & $\mathrm{b}$ & $\mathrm{b}$ & a & $\mathrm{b}$ & c \\
\hline $\mathbf{b}^{*}$ & a & $\mathrm{b}$ & c & a & $\mathrm{b}$ & $\mathrm{b}$ & $\mathrm{a}$ & $\mathrm{b}$ & $\mathrm{b}$ & a & $\mathrm{b}$ & C \\
\hline$C^{*}$ & a & $\mathrm{b}$ & c & a & $\mathrm{b}$ & $b$ & $\mathrm{a}$ & $\mathrm{b}$ & $\mathrm{b}$ & a & $\mathrm{b}$ & c \\
\hline TPI & a & $\mathrm{b}$ & $\mathrm{b}$ & $\mathrm{a}$ & $\mathrm{b}$ & $\mathrm{b}$ & $\mathrm{a}$ & $\mathrm{b}$ & $\mathrm{b}$ & a & $\mathrm{b}$ & $\mathrm{b}$ \\
\hline Furf & a & $\mathrm{a}$ & $\mathrm{a}$ & a & $\mathrm{a}$ & a & $\mathrm{a}$ & $a b$ & $\mathrm{~b}$ & a & $a b$ & $\mathrm{~b}$ \\
\hline Ellag & a & $\mathrm{b}$ & $\mathrm{b}$ & a & $\mathrm{b}$ & c & $\mathrm{a}$ & $\mathrm{b}$ & $\mathrm{b}$ & a & $\mathrm{b}$ & C \\
\hline Vanil & a & $\mathrm{b}$ & c & a & $\mathrm{b}$ & c & $\mathrm{a}$ & $\mathrm{b}$ & $\mathrm{b}$ & a & $\mathrm{b}$ & c \\
\hline Cofde & a & $\mathrm{a}$ & $\mathrm{a}$ & a & $\mathrm{b}$ & $\mathrm{b}$ & $\mathrm{a}$ & $\mathrm{b}$ & $\mathrm{a}$ & a & $\mathrm{b}$ & c \\
\hline sumHPLC & a & $\mathrm{b}$ & $\mathrm{b}$ & a & $\mathrm{a}$ & $\mathrm{a}$ & $\mathrm{a}$ & $\mathrm{b}$ & $\mathrm{b}$ & a & $\mathrm{b}$ & $\mathrm{b}$ \\
\hline
\end{tabular}

The spectra obtained for wine spirit are similar to those reported by others authors [28]. 
The representative absorbance spectra of wine spirit samples studied is plotted in Figure 2; their spectral information is in accordance with previous reports of other authors [48]. The IR region from 2990 to $3626 \mathrm{~cm}^{-1}$ has a very strong influence due to water present in the samples [49]. Nevertheless, for these analyses, the background was measured with water.

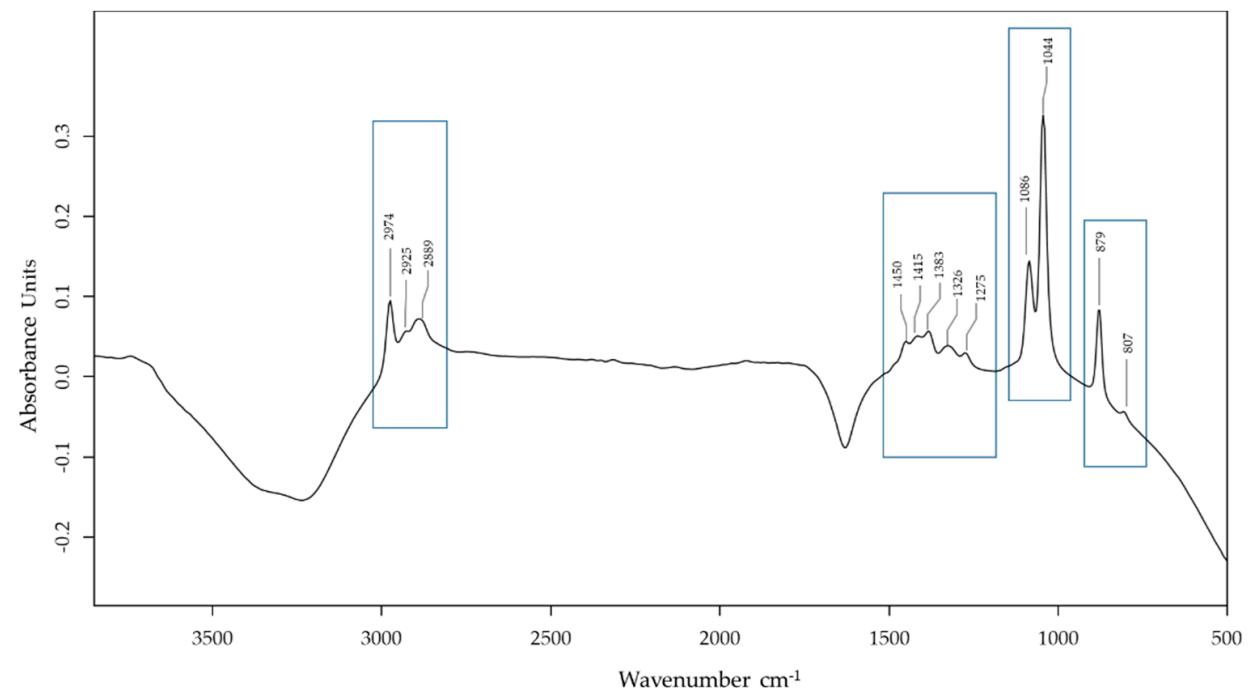

Figure 2. Fourier transform infrared spectroscopy-Attenuated Total Reflection (FTIR-ATR) absorbance spectra of wine spirit samples.

There is IR information in the regions from 3000 to $2900 \mathrm{~cm}^{-1}$ due to the $\mathrm{O}-\mathrm{H}$ stretching of alcohols and $\mathrm{C}-\mathrm{H}$ stretching of $\mathrm{CH}_{3}$ and $\mathrm{CH}_{2}$, and consequently related to the presence of ethanol and methanol in the alcoholic beverages [49].

Regarding the region from 1500 to $860 \mathrm{~cm}^{-1}$, it corresponds to $\mathrm{C}-\mathrm{C}$ and $\mathrm{C}-\mathrm{O}$ vibrations in volatile compounds [12,14].

The small peak at $1450 \mathrm{~cm}^{-1}$ was assigned to $\mathrm{C}-\mathrm{OH}$ bending deformation, and the peak at 1275 was assigned to $\mathrm{C}-\mathrm{O}$ stretching in the acid molecules [11,50].

According to Stuart (2004), the region from 1300 to $840 \mathrm{~cm}^{-1}$ shows other absorption bands assigned to the $\mathrm{C}=\mathrm{O}$ and $\mathrm{C}=\mathrm{C}$ groups present in furanic compounds. The highest peaks at 1086 and $1044 \mathrm{~cm}^{-1}$ are ascribed to the $\mathrm{C}-\mathrm{O}$ stretch absorption bands, which are important regions for ethanol and methanol identification and quantification respectively, and $\mathrm{C}-\mathrm{C}$ absorption bands, which are related to ethanol and some organic compounds such as sugars, phenols, alcohols, and esters $[14,49,51]$.

The peak at $879 \mathrm{~cm}^{-1}$ could be ascribed to out-of-plane $\mathrm{C}-\mathrm{H}$ bending of aromatic compounds [10], and to $\mathrm{CH}-\mathrm{OH}, \mathrm{C}-\mathrm{C}, \mathrm{C}-\mathrm{O}$, and $\mathrm{C}-\mathrm{H}$ bond stretching due to water, sugars, and phenolic compounds [51].

According to these regions of the FTIR-ATR absorption spectra (with baseline correction) of the wine spirit, a mathematical analysis has been performed to determine the differences between the groups studied. On the one hand, a functional ANOVA (FANOVA) model has been considered using two different tests: FP, the permutation test based on a representation of the base function (Equation (9)); and FB, the F test with the reduced bias estimation method (Equation (11)). On the other hand, a vector analysis based on the classical Analysis of Variance and the non-parametric Kruskal test have been carried out. Although all the areas of the curves have been analysed following the same process, only two were plotted each time to show the differences between the samples (space problem).

First, the different groups based on the ageing technology and kind of wood (AC, AL, TC, and TL) were tested. The contrast is different for each ageing time (18 months, 12 months, and 6 months). With an 18-month period, the hypothesis of similarity between all groups is rejected in all areas of the whole curve and from both points of view (Table 4). The samples of wine spirits aged by the alternative technology, on average, have higher absorbance units than the aged by the traditional one. Within the alternative technology, the wine spirit aged in oak wood always showed higher absorbance units 
than the one aged in chestnut wood (Figure 3). With an ageing period of 12 months, the similarity hypothesis is also rejected in all areas by the two analyses (Table 4). Even so, in this case, the differences between alternative and traditional ageing technologies are small. The spectrometric curves can hardly be differentiated in the functional part of Figure 4, and the $p$-values obtained are higher (Table 4). With an ageing time of 6 months, significant reasons were found to reject the similarity hypothesis in all areas through functional and vector analysis (Table 4). With this sample, the difference is more significant than with the 12-month sample but less than with the 18-month sample. Moreover, it can be seen that the wine spirit that gets higher absorbance units in the alternative sample is the one aged in oak, but with the traditional sample, it is the one aged in chestnut (Figure 5). These results are in accordance with those previously observed for the colour and analytical parameters (Tables 1 and 2).

Table 4. Numerical results of the similarity contrast between the groups AC, AL, TC, and TL, depending on the ageing time of the wine spirit samples. Functional results (FDA) are based on FANOVA using two different tests (FP: permutation test based on a representation of the base function, FB: F test with a reduced bias estimation method). In addition, the results of the ANOVA and Kruskal's test representing the vectorial results (VA) are shown. All the results are $p$-values based on a $5 \%$ significance level.

\begin{tabular}{|c|c|c|c|c|c|c|}
\hline \multicolumn{3}{|c|}{ TEST $\backslash$ SAMPLE } & $3050-2750 \mathrm{~cm}^{-1}$ & $1525-120 \mathrm{~cm}^{-1}$ & $1150-960 \mathrm{~cm}^{-1}$ & $910-750 \mathrm{~cm}^{-1}$ \\
\hline & & & \multicolumn{4}{|c|}{18 months } \\
\hline \multirow{2}{*}{ FDA } & \multirow{2}{*}{ FANOVA } & FP & $\approx 0$ & $\approx 0$ & $\approx 0$ & $\approx 0$ \\
\hline & & FB & $\approx 0$ & $\approx 0$ & $\approx 0$ & $\approx 0$ \\
\hline \multirow{3}{*}{ VA } & \multirow{2}{*}{\multicolumn{2}{|c|}{$\begin{array}{c}\text { ANOVA } \\
\text { Kruskal }\end{array}$}} & $\approx 0$ & $\approx 0$ & $\approx 0$ & $\approx 0$ \\
\hline & & & $\approx 0$ & $\approx 0$ & $\approx 0$ & $\approx 0$ \\
\hline & \multicolumn{2}{|c|}{ Kruskal } & \multicolumn{4}{|c|}{12 months } \\
\hline \multirow{2}{*}{ FDA } & \multirow{2}{*}{ FANOVA } & FP & 0.001 & $\approx 0$ & $\approx 0$ & $\approx 0$ \\
\hline & & FB & 0.003 & $\approx 0$ & $1.31 \times 10^{-5}$ & $\approx 0$ \\
\hline \multirow{3}{*}{ VA } & \multirow{2}{*}{\multicolumn{2}{|c|}{$\begin{array}{l}\text { ANOVA } \\
\text { Kruskal }\end{array}$}} & 0.007 & $\approx 0$ & 0.003 & $\approx 0$ \\
\hline & & & 0.008 & $2.23 \times 10^{-6}$ & 0.003 & $\approx 0$ \\
\hline & & & \multicolumn{4}{|c|}{6 months } \\
\hline \multirow{2}{*}{ FDA } & \multirow{2}{*}{ FANOVA } & FP & $\approx 0$ & $\approx 0$ & $\approx 0$ & $\approx 0$ \\
\hline & & FB & $\approx 0$ & $\approx 0$ & $\approx 0$ & $1 \times 10^{-4}$ \\
\hline \multirow{2}{*}{ VA } & \multirow{2}{*}{\multicolumn{2}{|c|}{$\begin{array}{l}\text { ANOVA } \\
\text { Kruskal }\end{array}$}} & $\approx 0$ & $\approx 0$ & $\approx 0$ & $\approx 0$ \\
\hline & & & $\approx 0$ & $\approx 0$ & $\approx 0$ & $\approx 0$ \\
\hline
\end{tabular}
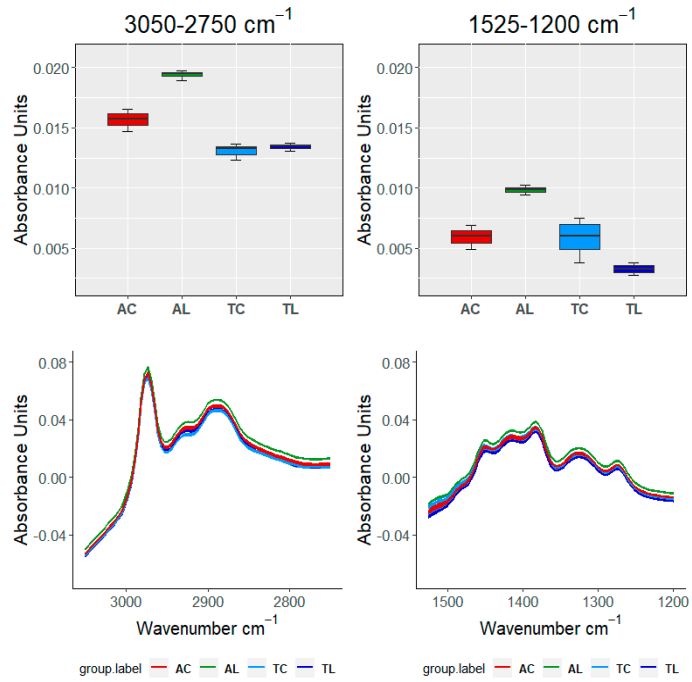

Figure 3. Plots of two of the four significant areas of the curves with an ageing time of 18 months. In the first row, vectorial analysis by means of boxplots. In the second row, functional data analysis (FDA) through curves in the studied interval. The wine spirit sample is divided into four groups $(\mathrm{AC}, \mathrm{AL}, \mathrm{TC}$, and TL). 

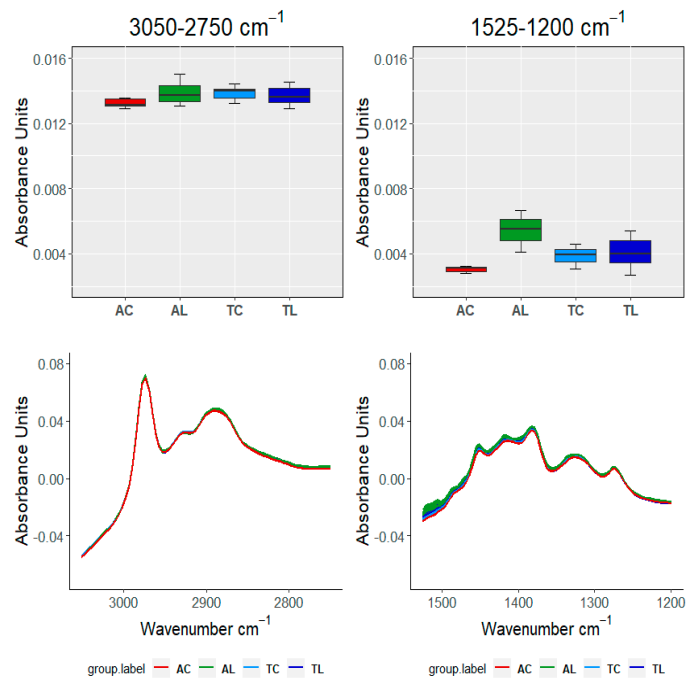

Figure 4. Plots of two of the four significant areas of the curves with an ageing time of 12 months. In the first row, vectorial analysis by means of boxplots. In the second row, FDA through curves in the studied interval. The wine spirit sample is divided into four groups (AC, AL, TC, and TL).
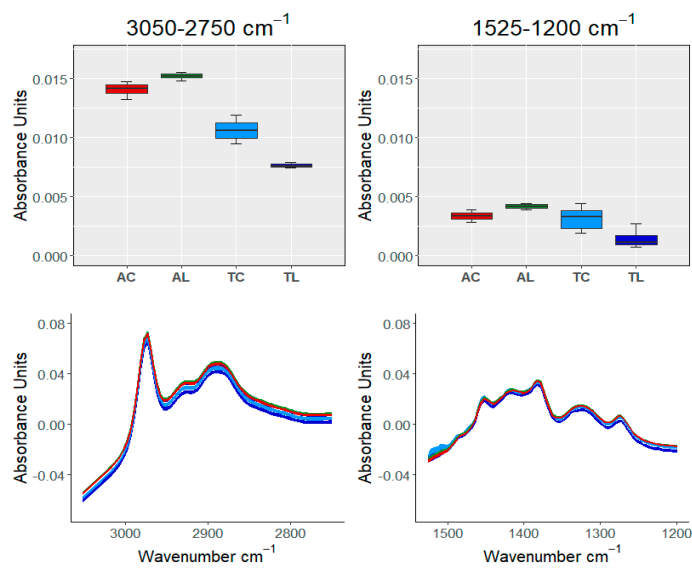

group.label $-\mathrm{AC}-\mathrm{AL}-\mathrm{TC}-$

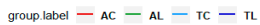

Figure 5. Plots of two of the four significant areas of the curves with an ageing time of 6 months. In the first row, vectorial analysis by means of boxplots. In the second row, FDA through curves in the studied interval. The wine spirit sample is divided into four groups (AC, AL, TC, and TL).

Secondly, the similarity between the three different ageing times was contrasted. This contrast is different depending on the ageing technology and kind of wood used (AC, AL, TC, and TL). Figure 6 shows the boxplots and curves of the sample resulting from alternative technology with chestnut wood. It can be seen that there is little difference between the three ageing times. Especially at the spectral region of $1150-960 \mathrm{~cm}^{-1}$ (second d column of Figure 6), in which the similarity hypothesis is rejected in the vector analysis. Instead, FDA is able to detect these differences between the curve samples (Table 5). This region is characteristic of the absorption bands assigned to $\mathrm{C}=\mathrm{O}$ and $\mathrm{C}=\mathrm{C}$ groups existing in furanic compounds, $\mathrm{C}-\mathrm{O}$ stretch absorption bands related to ethanol and methanol, and $\mathrm{C}-\mathrm{C}$ absorption bands also related to ethanol and some organic compounds such as sugars, phenols, alcohols, and esters previously reported, and all of them are important to differentiate the samples in this study. They are mainly identified at the peaks of the $1044 \mathrm{~cm}^{-1}$ and $1086 \mathrm{~cm}^{-1}$, which are chiefly related to the presence of ethanol and methanol but also related to some organic compounds such as sugars, phenols, alcohols, and esters existing in minor concentration in the beverages. In addition, similarity in the other areas of the entire curve within the sample resulting from alternative technology with chestnut wood is rejected. In the case of the alternative technology, the wine spirits aged with 
Limousin oak wood are very similar to those aged with chestnut wood but with more distance between the three ageing times (Figure 7), as observed in the chemical analysis. The similarity hypothesis is rejected in all areas and from both points of view (Table 5). Figure 8 shows the differentiation within the samples resulting from chestnut barrels. In this case, the two areas drawn from the whole curve are closer, but the differences between the three ageing times are greater. The hypothesis of similarity between the samples is rejected in all areas and from the vectorial and functional approach (Table 5). Finally, regarding the wine spirits aged in Limousin oak barrels, the 18 and 12-month samples show higher absorbance units than the 6-month sample (Figure 9). The spectrometric curves of the functional graph can be easily distinguished. There are significant reasons to reject the similarity between the three samples in all areas of the full curve from the two analyses (Table 5).
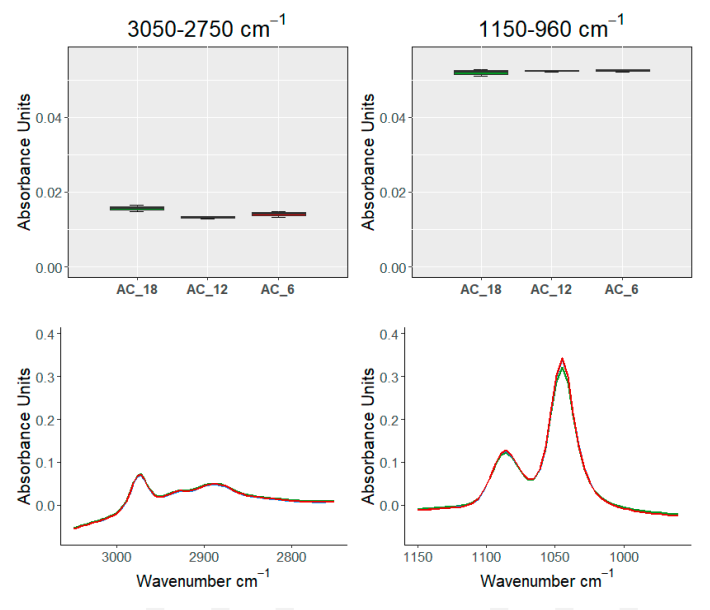

Figure 6. Plots of two of the four significant areas of the Alternative Chestnut (AC) curves. In the first row, vectorial analysis by means of boxplots. In the second row, FDA through curves in the studied interval. The wine spirit sample is divided into three groups depending on the ageing time $(18,12$, and 6 months of ageing).
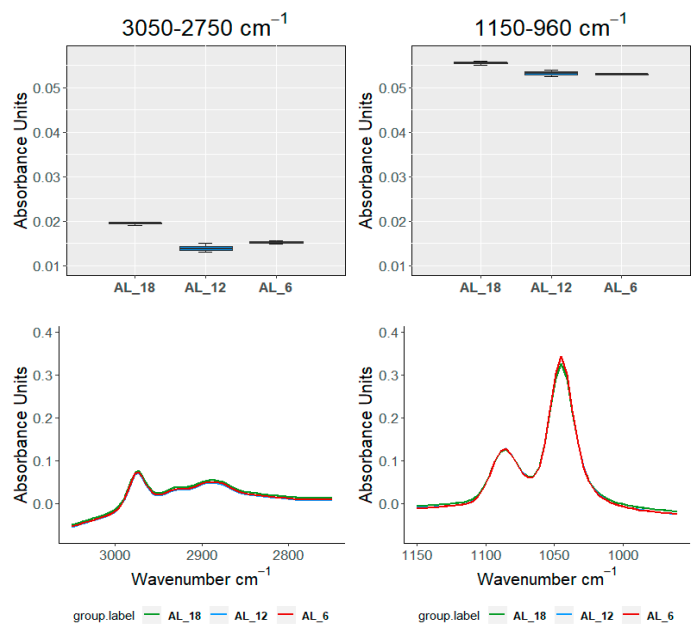

Figure 7. Plots of two of the four significant areas of the Alternative Oak (AL) curves. In the first row, vectorial analysis by means of boxplots. In the second row, FDA through curves in the studied interval. The wine spirit sample is divided into three groups depending on the ageing time $(18,12$, and 6 months of ageing). 
Table 5. Results of the similarity contrast between the three ageing times (18 months, 12 months, and 6 months), depending on the ageing technology. Functional results (FDA) are based on functional ANOVA (FANOVA) using two different tests (FP: permutation test based on a representation of the base function, FB: F test with a reduced bias estimation method). In addition, the results of the ANOVA and Kruskal's test representing the vectorial results (VA) are shown. All the results are $p$-values based on a $5 \%$ significance level.

\begin{tabular}{|c|c|c|c|c|c|c|}
\hline \multirow{2}{*}{\multicolumn{3}{|c|}{ TEST $\backslash$ SAMPLE }} & $3050-2750 \mathrm{~cm}^{-1}$ & $1525-120 \mathrm{~cm}^{-1}$ & $1150-960 \mathrm{~cm}^{-1}$ & $910-750 \mathrm{~cm}^{-1}$ \\
\hline & & & \multicolumn{4}{|c|}{ Groups within AC } \\
\hline \multirow{2}{*}{ FDA } & \multirow{2}{*}{ FANOVA } & FP & $\approx 0$ & $\approx 0$ & $\approx 0$ & $\approx 0$ \\
\hline & & FB & $\approx 0$ & $\approx 0$ & $\approx 0$ & $\approx 0$ \\
\hline \multirow{3}{*}{ VA } & \multirow{2}{*}{\multicolumn{2}{|c|}{$\begin{array}{l}\text { ANOVA } \\
\text { Kruskal }\end{array}$}} & $\approx 0$ & $\approx 0$ & 0.032 & $\approx 0$ \\
\hline & & & $\approx 0$ & $6.72 \times 10^{-5}$ & 0.214 & $1 \times 10^{-4}$ \\
\hline & & & \multicolumn{4}{|c|}{ Groups within AL } \\
\hline \multirow[b]{2}{*}{ FDA } & \multirow{2}{*}{ FANOVA } & FP & $\approx 0$ & $\approx 0$ & $\approx 0$ & $\approx 0$ \\
\hline & & FB & $\approx 0$ & $\approx 0$ & $\approx 0$ & $\approx 0$ \\
\hline \multirow{3}{*}{ VA } & \multirow{2}{*}{\multicolumn{2}{|c|}{$\begin{array}{l}\text { ANOVA } \\
\text { Kruskal }\end{array}$}} & $\approx 0$ & $\approx 0$ & $\approx 0$ & $\approx 0$ \\
\hline & & & $2.07 \mathrm{e}-06$ & $4.14 \times 10^{-6}$ & $3.34 \times 10^{-5}$ & $3.71 \times 10^{-6}$ \\
\hline & & & \multicolumn{4}{|c|}{ Groups within TC } \\
\hline \multirow{2}{*}{ FDA } & \multirow{2}{*}{ FANOVA } & FP & $\approx 0$ & $\approx 0$ & $\approx 0$ & $\approx 0$ \\
\hline & & FB & $\approx 0$ & $\approx 0$ & $\approx 0$ & $\approx 0$ \\
\hline \multirow{3}{*}{ VA } & \multirow{2}{*}{\multicolumn{2}{|c|}{$\begin{array}{l}\text { ANOVA } \\
\text { Kruskal }\end{array}$}} & $\approx 0$ & $\approx 0$ & $\approx 0$ & $\approx 0$ \\
\hline & & & $\approx 0$ & $7.32 \times 10^{-6}$ & $\approx 0$ & $\approx 0$ \\
\hline & & & & Groups & thin TL & \\
\hline \multirow{2}{*}{ FDA } & \multirow{2}{*}{ FANOVA } & FP & $\approx 0$ & $\approx 0$ & $\approx 0$ & $\approx 0$ \\
\hline & & FB & $\approx 0$ & $\approx 0$ & $\approx 0$ & $\approx 0$ \\
\hline \multirow{2}{*}{ VA } & \multirow{2}{*}{\multicolumn{2}{|c|}{$\begin{array}{l}\text { ANOVA } \\
\text { Kruskal }\end{array}$}} & $\approx 0$ & $\approx 0$ & $\approx 0$ & $\approx 0$ \\
\hline & & & $1 \times 10^{-4}$ & $1.95 \times 10^{-6}$ & $\approx 0$ & $\approx 0$ \\
\hline
\end{tabular}
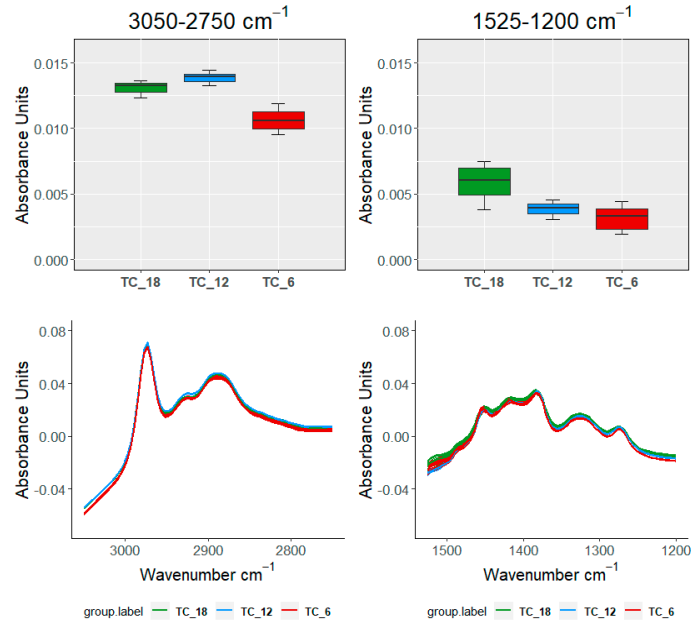

Figure 8. Plots of two of the four significant areas of the Traditional Chestnut (TC) curves. In the first row, vectorial analysis by means of boxplots. In the second row, FDA through curves in the studied interval. The wine spirit sample is divided into three groups depending on the ageing time $(18,12$, and 6 months of ageing). 

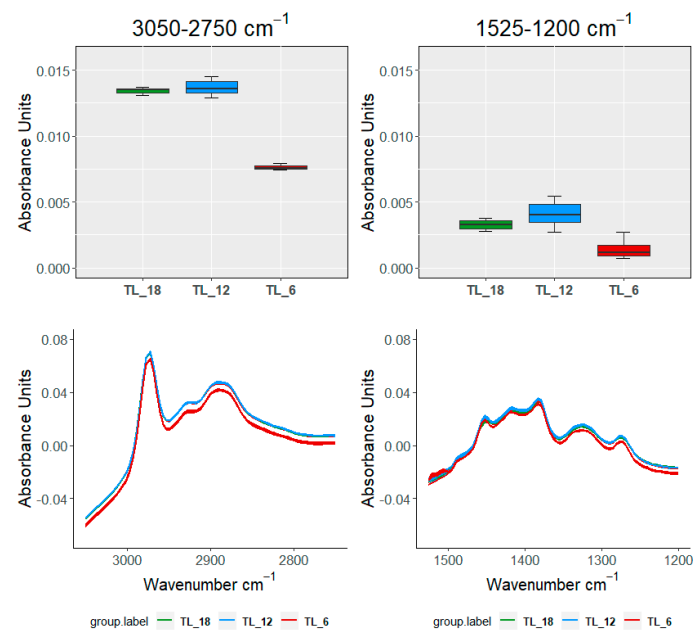

Figure 9. Plots of two of the four significant areas of the Traditional Oak (TL) curves. In the first row, vectorial analysis by means of boxplots. In the second row, FDA through curves in the studied interval. The wine spirit sample is divided into three groups depending on the ageing time $(18,12$, and 6 months of ageing).

\section{Discussion}

The colour and total phenolic content acquired by the wine spirits during the ageing process (Table 1) are in line with the wine spirits' features observed in the first six months of ageing [8], and they are also in accordance with those of recent ageing studies of brandy [2,3]. The colour acquisition has been assigned to extraction, oxidation, and other physicochemical phenomena occurring during ageing $[8,52]$. Hence, more marked color development in the wine spirits aged by the alternative technology, and with chestnut wood, may have resulted from the direct application of oxygen [8] and/or from more oxygen transferred by this kind of wood due to its higher porosity [53], which may have favored such phenomena. Regarding the total phenolic content (TPI), a consistent behavior with the chromatic characteristics was found, reinforcing previous results [8]: there is a correlation between the enrichment in phenolic compounds and the colour acquired, which are induced by the ageing technology and the kind of wood.

Accordingly, the total content of low molecular weight compounds (phenolic acids, phenolic aldehydes, coumarins, and furanic aldehydes) concentrations determined by HPLC (Table 2) acted as distinctive feature of the aged wine spirits, which can be ordered as follows: AC $>$ AL $\sim$ TC $>$ TL. Therefore, the pattern reported for the first six months of ageing [8] prevailed until the end of the ageing process (18 months).

Low molecular weight compounds, such as furfural, ellagic acid, vanillin, and coniferaldehyde, as aforementioned, stood out as markers of the ageing technology (Table 2). Similar results for these wood-derived phenolic compounds [1,54] were obtained in the beginning of ageing [8]. Their higher accumulation in wine spirits resulting from the alternative technology has been ascribed to a faster extraction from the wood, as described by other authors for the ageing of red wine with wood pieces $[55,56]$; the behavior of coniferaldehyde is explained by its sensitivity towards oxidation.

The evolution observed for the colour parameters over the ageing process was supported by the progressive increase of the total phenolic content (TPI) and particularly the low molecular weight compounds quantified by HPLC (sumHPLC), which reflected the release of the wood-derived compounds into the wine spirit together with a positive balance between their formation/degradation [4] in the liquid medium. The kinetics of individual compounds shows a continuous increment of ellagic acid content, regardless of the assay modality, which may have resulted from the release of this phenolic acid existing in the wood [1] and from the oxidation and hydrolysis of ellagitannins in the wine spirit during ageing $[57,58]$. The kinetics of vanillin presented a similar pattern, which was likely due to its release from the wood [59], lignin's hydroalcoholysis, and subsequent oxidation 
reactions that converted coniferaldehyde into vanillin in the wine spirit [4]. Interestingly, there was an increase of coniferaldehyde content between 6 and 12 months followed by a decrease until 18 months. This suggests that after 12 months of ageing, oxidation reactions prevailed over extraction and lignin's hydroalcoholys is causing an unbalance between coniferaldehyde formation and degradation. Similar results were previously noticed for wine spirits aged by the alternative technology but without micro-oxygenation and also by the traditional ageing in wooden barrels [4]. The evolution of furfural content was different from those of phenolic compounds. Indeed, its kinetics was closely related to the ageing technology: there was an increase from 6 to 12 months and then a decrease in wine spirits aged by the alternative technology; the opposite behavior occurred in wine spirits aged by the traditional one (TC and TL).

The statistical analyses performed during the ageing time reveals significant differences between 6 months and 12 months in a higher number of parameters than the observed between 12 months and 18 months. However, for the wine spirits aged by the alternative technology with Limousin staves significant differences between the three sampling times were observed. Regarding the alternative technology, these outcomes suggest that one year is enough/adequate to obtain a high-quality wine spirit aged with micro-oxygenation and chestnut staves as a consequence of higher pool of compounds and specific anatomical properties of this kind of wood compared with the Limousin oak wood $[2,60]$.

The mathematical analysis performed with functional and vectorial approach corroborates the findings about colour parameters, total phenolic content, and low molecular weight compounds. According to the mathematical analysis, two main conclusions have been reached. First, there are significant reasons to reject the similarity between the wine spirits samples differentiated according to the ageing technology used. It was rejected in all areas of the full spectrometric curve for each of the three ageing times tested, both in vector and functional data analysis. Secondly, evidence was found to state that the samples of wine spirits with different ageing time are not similar. The similarity hypothesis between the three ageing times for each of the different technologies (traditional vs. alternative) used was rejected in all the areas of the spectrometric curve analysed.

On the other hand, FDA shows higher consistency than the vector analysis as observed by Martínez et al. $[15,20]$. In addition, to provide more information and accuracy, FDA can detect significant differences between groups that vector analysis cannot. This can be seen in the sample obtained by alternative technology with chestnut wood, specifically in the spectral region of $1150-960 \mathrm{~cm}^{-1}$ of $^{-15}$ the entire curve. It is attributed to the functional groups present in furanic compounds and also related to ethanol, methanol, and sugars, phenols, and esters existing in the wine spirit $[1,4,5,8,14,49,51]$. Vector analysis found no evidence to reject the similarity between the samples based on ageing time, but FDA, taking into account all correlated observations measured in the specific area, did.

\section{Conclusions}

The aged wine spirit composition and quality depend on the raw material, but mainly on the ageing technology, the wood species used in the ageing process, and the ageing time. Monitoring this quality over time with a fast methodology is very important for the industry.

This study showed a remarkable congruence between the analytical determinations (colour, total phenolic index, and low molecular weight compounds) and the FTIR-ATR/mathematical approach in the differentiation of wine spirits aged by the alternative (micro-oxygenation combined with wood pieces in stainless steel tanks) and the traditional (wooden barrels) technologies, using two kinds of wood (chestnut and oak), over the ageing time (6,12, and 18 months). Additionally, the analytical results suggest that one year is enough/adequate to achieve a high-quality wine spirit aged with micro-oxygenation and chestnut staves.

FTIR-ATR with appropriate chemometric techniques, specifically functional data analysis, and vector analysis proved to be a powerful tool for an easier and faster monitoring of the wine spirit's ageing process. FDA showed higher consistency than the vector analysis, providing more information and accuracy; it detected significant differences between groups that the vector analysis did not detect. 
It was clearly demonstrated in the sample resulting from the alternative technology with chestnut wood, specifically in the area $1150-960 \mathrm{~cm}^{-1}$ of the entire curve. Vector analysis found no evidence to reject similarity between the time ageing samples, but FDA, taking into account all correlated observation measured in the specific area, found it.

It was also possible to identify the more accurate spectral region to perform a calibration model to be applied by the wine spirit industry.

Author Contributions: Conceptualisation, O.A. and S.C.; methodology, O.A., S.C., M.M.C., P.E.O.; formal analysis, S.C., O.A., I.C., S.I.P.; Statistical analysis: M.M.C., P.E.O., O.A.; investigation, S.C., O.A., I.C., S.I.P.; resources, S.C.; O.A.; writing, O.A., M.M.C., S.C.; supervision, O.A.; project administration, S.C.; funding acquisition, S.C. All authors have read and agreed to the published version of the manuscript.

Funding: This research was funded by the Project CENTRO-04-3928-FEDER 0000281/Line "Validation of a new ageing technology for wine spirit from Lourinhã". This work is also funded by National Funds through FCT-Foundation for Science and Technology under the Project UIDB/05183/2020 (MED-Mediterranean Institute for Agriculture, Environment and Development) and the Project UIDB/00239/2020 (Centro de Estudos Florestais).

Acknowledgments: The authors thank João Pedro Catela, Nádia Santos, Manuela Gomes, Eugénia Gomes and Inês Antunes from Adega Cooperativa da Lourinhã, and Tanoaria J.M. Gonçalves for the technical support.

Conflicts of Interest: The authors declare no conflict of interest.

\section{References}

1. Canas, S. Phenolic Composition and Related Properties of Aged Wine Spirits: Influence of Barrel Characteristics. A Review. Beverages 2017, 3, 55. [CrossRef]

2. García-Moreno, M.V.; Sánchez-Guillén, M.M.; Mier, M.R.D.; Delgado-González, M.J.; Rodríguez-Dodero, M.C.; García-Barroso, C.; Guillén-Sánchez, D.A. Use of Alternative Wood for the Ageing of Brandy de Jerez. Foods 2020, 9, 250. [CrossRef] [PubMed]

3. Schwarz, M.; Rodríguez-Dodero, C.M.; Jurado, S.M.; Puertas, B.G.; Barroso, C.; Guillén, A.D. Analytical Characterization and Sensory Analysis of Distillates of Different Varieties of Grapes Aged by an Accelerated Method. Foods 2020, 9, 277. [CrossRef] [PubMed]

4. Canas, S.; Caldeira, I.; Belchior, A.P. Extraction/oxidation kinetics of low molecular weight compounds in wine brandy resulting from different ageing technologies. Food Chem. 2013, 138, 2460-2467. [CrossRef]

5. Caldeira, I.; Santos, R.; Ricardo-da-Silva, J.M.; Anjos, O.; Mira, H.; Belchior, A.P.; Canas, S. Kinetics of odorant compounds in wine brandies aged in different systems. Food Chem. 2016, 211, 937-946. [CrossRef]

6. Rodríguez-Solana, R.; Rodríguez-Freigedo, S.; Salgado, J.M.; Domínguez, J.M.; Cortés-Diéguez, S. Optimisation of accelerated ageing of grape marc distillate on a micro-scale process using a Box-Benhken design: Influence of oak origin, fragment size and toast level on the composition of the final product. Aust. J. Grape Wine Res. 2017, 23, 5-14. [CrossRef]

7. Gómez-Plaza, E.; Bautista-Ortín, A.B. Chapter 10-Emerging Technologies for Aging Wines: Use of Chips and Micro-Oxygenation. In Red Wine Technology; Morata, A., Ed.; Academic Press: Cambridge, MA, USA, 2019; pp. 149-162. [CrossRef]

8. Canas, S.; Caldeira, I.; Anjos, O.; Belchior, A. Phenolic profile and colour acquired by the wine spirit in the beginning of ageing: Alternative technology using micro-oxygenation vs traditional technology. LWT Food Sci. Technol. 2019, 111, 260-269. [CrossRef]

9. Llario, R.; Iñón, F.A.; Garrigues, S.; de la Guardia, M. Determination of quality parameters of beers by the use of attenuated total reflectance-Fourier transform infrared spectroscopy. Talanta 2006, 69, 469-480. [CrossRef]

10. Yadav, P.K.; Sharma, R.M. Classification of illicit liquors based on their geographic origin using Attenuated total reflectance (ATR)-Fourier transform infrared (FT-IR) spectroscopy and chemometrics. Forensic Sci. Int. 2019, 295, e1-e5. [CrossRef]

11. Nagarajan, R.; Mehrotra, R.; Bajaj, M.M. Quantitative analysis of methanol, an adulterant in alcoholic beverages, using attenuated total reflectance spectroscopy. J. Sci. Ind. Res. 2006, 65, 416-419.

12. Teodora Emilia, C.; Carmen, S.; Florinela, F.; FloricuÅ£a, R.; Raluca Maria, P.O.P.; Mira, F. Rapid Quantitative Analysis of Ethanol and Prediction of Methanol Content in Traditional Fruit Brandies from Romania, using FTIR Spectroscopy and Chemometrics. Not. Bot. Horti Agrobot. Cluj-Napoca 2013, 41. [CrossRef] 
13. Wiśniewska, P.; Boqué, R.; Borràs, E.; Busto, O.; Wardencki, W.; Namieśnik, J.; Dymerski, T. Authentication of whisky due to its botanical origin and way of production by instrumental analysis and multivariate classification methods. Spectrochim. Acta. Part A Mol. Biomol. Spectrosc. 2017, 173, 849-853. [CrossRef] [PubMed]

14. Anjos, O.; Santos, A.J.A.; Estevinho, L.M.; Caldeira, I. FTIR-ATR spectroscopy applied to quality control of grape-derived spirits. Food Chem. 2016, 205, 28-35. [CrossRef] [PubMed]

15. Martínez Comesaña, M.; Martínez Mariño, S.; Eguía Oller, P.; Granada Álvarez, E.; Erkoreka González, A. A Functional Data Analysis for Assessing the Impact of a Retrofitting in the Energy Performance of a Building. Mathematics 2020, 8, 547. [CrossRef]

16. Martínez, J.; Ordoñez, C.; Matìas, J.M.; Taboada, J. Determining noise in an aggregates plant using functional statistics. Hum. Ecol. Risk Assess. 2011, 17, 521-533. [CrossRef]

17. Müller, H.-G.; Sen, R.; Stadtmüller, U. Functional data analysis for volatility. J. Econom. 2011, 165, $233-245$. [CrossRef]

18. López, M.; Martínez, J.; Matías, J.M.; Taboada, J.; Vilán, J.A. Shape functional optimization with restrictions boosted with machine learning techniques. J. Comput. Appl. Math. 2010, 234, 2609-2615. [CrossRef]

19. Sancho, J.; Pastor, J.J.; Martínez, J.; García, M.A. Evaluation of Harmonic Variability in Electrical Power Systems through Statistical Control of Quality and Functional Data Analysis. Procedia Eng. 2013, 63, $295-302$. [CrossRef]

20. Martínez, J.; Pastor, J.; Sancho, J.; McNabola, A.; Martínez, M.; Gallagher, J. A functional data analysis approach for the detection of air pollution episodes and outliers: A case study in Dublin, Ireland. Mathematics 2020, 8, 225. [CrossRef]

21. Di Battista, T.; Fortuna, F. Functional confidence bands for lichen biodiversity profiles: A case study in Tuscany region (central Italy). Stat. Anal. Data Min. ASA Data Sci. J. 2017, 10, 21-28. [CrossRef]

22. Ruiz-Bellido, M.A.; Romero-Gil, V.; García-García, P.; Rodríguez-Gómez, F.; Arroyo-López, F.N.; Garrido-Fernández, A. Data on the application of Functional Data Analysis in food fermentations. Data Brief 2016, 9, 401-412. [CrossRef] [PubMed]

23. Ordoñez, C.; Martínez, J.; Matías, J.M.; Reyes, A.N.; Rodríguez-Pérez, J.R. Functional statistical techniques applied to vine leaf water content determination. Math. Comput. Model. 2010, 52, 1116-1122. [CrossRef]

24. Crawley, M.J. The R Book; John Wiley \& Sons: Hoboken, NJ, USA, 2013.

25. Montgomery, D.C. Design and Analysis of Experiments; John Wiley \& Sons, Inc.: Hoboken, NJ, USA, 2013.

26. Ostertagová, E.; Ostertag, O.; Kovác, J. Methodology and application of the Kruskal-Wallis test. Appl. Mech. Mater. 2014, 611, 115-120. [CrossRef]

27. Cetó, X.; Gutiérrez, J.M.; Gutiérrez, M.; Céspedes, F.; Capdevila, J.; Mínguez, S.; Jiménez-Jorquera, C.; del Valle, M. Determination of total polyphenol index in wines employing a voltammetric electronic tongue. Anal. Chim. Acta 2012, 732, 172-179. [CrossRef]

28. Canas, S.; Belchior, A.; Spranger, M.; Sousa, R. High-performance liquid chromatography method for analysis of phenolic acids, phenolic aldehydes, and furanic derivatives in brandies. Development and validation. J. Sep. Sci. 2003, 26, 496-502. [CrossRef]

29. Martínez, J.; Saavedra, Á.; García, P.J.; Piñeiro, J.I.; Iglesias, C.; Taboada, J.; Sancho, J.; Pastor, J. Air quality parameters outliers detection using functional data analysis in the Langreo urban area (Northern Spain). Appl. Math. Comput. 2014, 241,1-10. [CrossRef]

30. Wang, J.L.; Chiou, J.M.; Müller, H.G. Functional Data Analysis. Annu. Rev. Stat. Appl. 2016, 3, $257-295$. [CrossRef]

31. Kramosil, I.; Michálek, J. Fuzzy metrics and statistical metric spaces. Kybernetika 1975, 11, 336-344.

32. Ramsay, J.O.; Silverman, B.W. Functional Data Analysis, 2nd ed.; Springer: New York, NY, USA, 2005.

33. Cormier, E.; Genest, C.; Nešlehová, J.G. Using B-splines for nonparametric inference on bivariate extreme-value copulas. Extremes 2014, 17, 633-659. [CrossRef]

34. Kwok, W.Y.; Moser, R.D.; Jiménez, J. A Critical Evaluation of the Resolution Properties of B-Spline and Compact Finite Difference Methods. J. Comput. Phys. 2001, 174, 510-551. [CrossRef]

35. Piñeiro, J.I.; Torres, J.M.; García, P.J.; Alonso, J.R.; Muñiz, C.D.; Taboada, J. Analysis and detection of functional outliers in waterquality parameters from different automated monitoring stationsin the Nalón River Basin (Northern Spain). Environ. Sci. Pollut. Res. Int. 2015, 22, 387-396. [CrossRef] [PubMed] 
36. Febrero, M.; Galeano, P.; Wenceslao, G.M. Outlier detection in functional data by depth measures, with application to identify abnormal NOx levels. Environmetrics 2008, 19, 331-345. [CrossRef]

37. Fraiman, R.; Muniz, G. Trimmed means for functional data. TEST 2001, 10, 419-440. [CrossRef]

38. Cuevas, A.; Febrero, M.; Fraiman, R. Robust estimation and classification for functional data via projection-based notions. Comput. Stat. 2007, 22, 481-496. [CrossRef]

39. Cuevas, A.; Febrero, M.; Fraiman, R. On the use of bootstrap for estimating functions with functional data. Comput. Stat. Data Anal. 2006, 51, 1063-1074. [CrossRef]

40. Millán-Roures, L.; Epifanio, I.; Martínez, V. Detection of Anomalies in Water Networks by Functional Data Analysis. Math. Probl. Eng. 2018, 2018, 13. [CrossRef]

41. Maturo, F.; Battista, T.; Fortuna, F. Parametric functional analysis of variance for fish biodiversity assessment. J. Environ. Inform. 2016, 28, 101-109. [CrossRef]

42. Cuesta-Albertos, J.A.; Febrero, M. A simple multiway ANOVA for functional data. TEST 2010, 19, 537-557. [CrossRef]

43. Zhang, J.-T. Analysis of Variance for Functional Data. In A Chapman \& Hall Book; Press, C.R.C., Ed.; Taylor \& Francis Group: Abingdon, UK, 2013; p. 412.

44. Aguilera, A.; Fortuna, F.; Escabias, M.; Battista, T. Assessing Social Interest in Burnout Using Google Trends Data. Soc. Indic. Res. 2019, 1-13. [CrossRef]

45. Górecki, T.; Smaga, Ł. fdANOVA: An R software package for analysis of variance for univariate and multivariate functional data. Comput. Stat. 2019, 34, 571-597. [CrossRef]

46. Zhang, J.-T. Statistical inferences for linear models with functional responses. Stat. Sin. 2011, 21, 1431-1451. [CrossRef]

47. Górecki, T.; Smaga, Ł. A comparison of tests for the one-way ANOVA problem for functional data. Comput. Stat. 2015, 30, 987-1010. [CrossRef]

48. Moreira, J.; Santos, L. Spectroscopic interferences in Fourier transform infrared wine analysis. Anal. Chim. Acta 2003, 513, 263-268. [CrossRef]

49. Shurvell, H.F. Spectra-Structure Correlations in the Mid- and Far-Infrared. In Handbook of Vibrational Spectroscopy; John Wiley \& Sons: Hoboken, NJ, USA, 2001.

50. Tarantilis, P.A.; Troianou, V.E.; Pappas, C.S.; Kotseridis, Y.S.; Polissiou, M.G. Differentiation of Greek red wines on the basis of grape variety using attenuated total reflectance Fourier transform infrared spectroscopy. Food Chem. 2008, 111, 192-196. [CrossRef]

51. Öztürk, B.; Yucesoy, D.; Ozen, B. Application of Mid-infrared Spectroscopy for the Measurement of Several Quality Parameters of Alcoholic Beverages, Wineand Raki. Food Anal. Methods 2012, 5, 1435-1442. [CrossRef]

52. Fujieda, M.; Tanaka, T.; Suwa, Y.; Koshimizu, S.; Kouno, I. Isolation and Structure of Whiskey Polyphenols Produced by Oxidation of Oak Wood Ellagitannins. J. Agric. Food. Chem. 2008, 56, 7305-7310. [CrossRef]

53. Carvalho, A. Identificação anatómica e caracterização física e mecânica das madeiras utilizadas no fabrico de quartolas para produção de aguardentes velhas de qualidade-Denominação Lourinhã. Ciência Técnica Vitivinícola 1998, 13, 71-105.

54. Martínez-Gil, A.; del Alamo-Sanza, M.; Sánchez-Gómez, R.; Nevares, I. Alternative Woods in Enology: Characterization of Tannin and Low Molecular Weight Phenol Compounds with Respect to Traditional Oak Woods. A Review. Molecules 2020, 25, 1474. [CrossRef]

55. Oberholster, A.; Elmendorf, B.L.; Lerno, L.A.; King, E.S.; Heymann, H.; Brenneman, C.E.; Boulton, R.B. Barrel maturation, oak alternatives and micro-oxygenation: Influence on red wine aging and quality. Food Chem. 2015, 173, 1250-1258. [CrossRef]

56. Laqui-Estaña, J.; López-Solís, R.; Peña-Neira, Á.; Medel-Marabolí, M.; Obreque-Slier, E. Wines in contact with oak wood: The impact of the variety (Carménère and Cabernet Sauvignon), format (barrels, chips and staves), and aging time on the phenolic composition. J. Sci. Food Agric. 2019, 99, 436-448. [CrossRef]

57. Karvela, E.; Makris, D.P.; Kefalas, P.; Moutounet, M. Extraction of phenolics in liquid model matrices containing oak chips: Kinetics, liquid chromatography-mass spectroscopy characterisation and association with in vitro antiradical activity. Food Chem. 2008, 110, 263-272. [CrossRef] [PubMed]

58. García-Estévez, I.; Alcalde-Eon, C.; Martínez-Gil, A.M.; Rivas-Gonzalo, J.C.; Escribano-Bailón, M.T.; Nevares, I.; del Alamo-Sanza, M. An Approach to the Study of the Interactions between Ellagitannins and Oxygen during Oak Wood Aging. J. Agric. Food. Chem. 2017, 65, 6369-6378. [CrossRef] [PubMed] 
59. Martínez-Gil, A.; Cadahía, E.; Fernández de Simón, B.; Gutiérrez-Gamboa, G.; Nevares, I.; del Álamo-Sanza, M. Phenolic and volatile compounds in Quercus humboldtii Bonpl. wood: Effect of toasting with respect to oaks traditionally used in cooperage. J. Sci. Food Agric. 2019, 99, 315-324. [CrossRef] [PubMed]

60. Anjos, O.; Carmona, C.; Caldeira, I.; Canas, S. Variation of Extractable Compounds and Lignin Contents in Wood Fragments Used in the Aging of Wine Brandies. BioResources 2013, 8, 4484-4496. [CrossRef]

(C) 2020 by the authors. Licensee MDPI, Basel, Switzerland. This article is an open access article distributed under the terms and conditions of the Creative Commons Attribution (CC BY) license (http://creativecommons.org/licenses/by/4.0/). 